\title{
A Successful Program to Promote Equity in Cancer Care for American Indians
}

\author{
Maria C. Bishop ${ }^{1} \cdot$ Margaret M. Briehl $^{2}$
}

Published online: 14 January 2022

(c) The Author(s) under exclusive licence to American Association for Cancer Education 2022

Disparities in cancer care have been acknowledged worldwide. Within the USA, some communities have been negatively affected by challenges to receiving cancer preventive screenings and cancer treatment. These communities include federally recognized sovereign tribal nations.

Although the American Cancer Society reports that the death rate for cancer in the USA continues to declinedecreasing $31 \%$ from 1991 to 2018 -this reduction in cancer mortality is not equal among all communities [1]. For example, reductions in cancer mortality rates have been greater for non-Hispanic white Americans compared with American Indians [2]. The underlying causes of this disparity are not fully understood. For American Indians living on tribal lands, possible contributing factors include delays in diagnosis, less access to cancer care and clinical trials, and limited healthcare literacy.

The state of Arizona is home to 22 federally recognized sovereign tribal nations. The Navajo nation is the largest, with nearly 200,000 people living on tribal lands. Overall cancer incidence is lower for American Indians than that for white Americans, but American Indians with cancer frequently have a shorter survival than white patients with cancer [3]. Among Navajo men, prostate cancer, colorectal cancer, and stomach cancer are the most common malignancies. Compared with non-Hispanic white men, the incidences of liver and stomach cancers are higher, and the incidences of prostate and colorectal cancers are lower in American Indians. Breast, ovarian, and colorectal cancers are the most common cancers for Navajo woman. Their

Maria C. Bishop

mbishop@email.arizona.edu

1 Section of Hematology and Oncology, University of Arizona Cancer Center, 1515 N Campbell Ave, PO Box 24-5024, Tucson, AZ 85724-5024, USA

2 Department of Pathology, University of Arizona, 1501 N Campbell Ave LSN 548, PO Box 24-5043, Tucson, AZ 85724-5043, USA incidence of stomach cancer is higher, and that for breast and colorectal cancers lower, compared with non-Hispanic white women [4].

Due to the long distances that Navajo patients have had to travel to receive cancer care, the new Tuba City Regional Health Care Corporation Specialty Care Center (TCRHCC) was built. Access to care was sensitively addressed in their 2018 video TCRHCC Priority for Cancer Treatment-Going the Distance: For Life [5]. In addition to improving access to care, however, there is a need to educate more American Indians to be cancer care providers and scientists. Increasing their representation in the workforce will improve the likelihood that the health needs of these underserved populations are met and cancer care disparities are eliminated.

Currently, there is a low number of American Indians with an advanced degree in the biomedical sciences [6]. The Association of American Medical Colleges reports that American Indians or Alaska Natives (AI/AN) represent $0.3 \%$ of physicians (in 2011-2015 US census data, American Indians represented $0.1 \%$ of physicians), whereas nonHispanic whites represent $56.2 \%$ of physicians [7]. Many students from underserved areas lack access to role models and mentors at critical stages in their education and training. Contributing to this challenge is the lack of opportunities to develop the skills needed to access mentors.

The low number of role models and mentors and limited skills to know how to meet mentors are problems not specific to American Indians. They are shared by many underserved communities across the USA and worldwide. The National Institutes of Health (NIH) has recognized this problem and developed funding mechanisms to address it. For example, NIH's Center to Reduce Cancer Health Disparities (CRCHD) funds grants of which a key aspect is the training of individuals from backgrounds underrepresented in cancer biomedical and behavioral sciences [8]. An essential component of these efforts is creating opportunities for trainees to develop effective mentoring relationships. 
The Partnerships to Advance Cancer Health Equity is one of the funding programs within the CRCHD. Each partnership pairs an institution serving an underserved population with a National Cancer Institute (NCI)-designated cancer center. In Arizona, the Partnership for Native American Cancer Prevention (NACP) [9] is a collaboration between Northern Arizona University, which serves American Indian students and communities, and the University of Arizona Comprehensive Cancer Center. The Research Education Core of NACP provides education, mentored research experiences, and career development opportunities for American Indians to pursue advanced degrees for providing cancer care and conducting cancer research.

As one approach to correcting the small number of role models and mentors for American Indian students, the NACP Research Education Core at the University of Arizona Cancer Center has offered the My Journey seminar series [10]. The goals of the series are to motivate students to continue along their educational paths and to help them network with AI/AN role models. Nine American Indian scientists at the career level of postdoctoral associate, assistant professor, or associate professor and 88 attendees participated in the series, which spanned 2 academic years beginning in April 2019. Each seminar started with a 1-h slide presentation, followed by a 1-h networking session. Seminar topics included psychology, environmental sciences, public health, and oncology, all from an Indigenous perspective. During the seminar, speakers described their personal journeys from their Native communities to their current career positions.

The results from evaluations showed the success of the My Journey series. All participants completed the postseminar evaluations. Sixty-four percent of the participants strongly agreed, and $23 \%$ of the participants agreed that they felt more encouraged to finish their degrees. Most participants also indicated increased interest in becoming researchers. The effectiveness of the seminar series as a way to introduce trainees to mentors was demonstrated by $85 \%$ of the participants agreeing or strongly agreeing that they would appreciate being able to network with the speakers. All participants indicated that they would attend future seminars in the series.

Cancer care disparities, low number of mentors, and limited skills to access mentors are not unique to American Indian tribes in Arizona. This is a universal need of underserved communities worldwide. The My Journey seminar series is one example of a successful program that can be generalized to other settings. It is a step in promoting cancer care equity.

Mentoring is at the core of who we are as educators and organizations. Skilled mentors and access to these mentors are essential to mitigate the disparities that our underserved populations are experiencing.

\section{References}

1. American Cancer Society (2021) Cancer facts \& figures 2021. American Cancer Society, Atlanta

2. Siegel RL, Jemal A, Wender RC, Gasler T, Ma J, Brawley OW (2018) An assessment of progress in cancer control. CA: Cancer J Clin 68:329-339. https://doi.org/10.3322/caac.21460

3. White MC, Espey DK, Swan J, Wiggins CL, Eheman C, Kaur JS (2014) Disparities in cancer mortality and incidence among American Indians and Alaska Natives in the United States. Am J Public Health 104(Suppl 3):S377-S387. https://doi.org/10.2105/ AJPH.2013.301673

4. Navajo Cancer Core Workgroup. Generating a tribe-specific cancer report for the Navajo Nation. http://nmcancercouncil.org/pdf/ Navajo-Cancer-Report-7-20-11.pdf. Accessed 6 Dec 2021

5. Tuba City Regional Health Care Corporation (2018) TCRHCC priority for cancer treatment- going the distance: for life. https:// www.tchealth.org/cancer/. Accessed 6 Dec 2021

6. National Science Foundation, National Center for Science and Engineering Statistics (2017) 2015 Doctorate recipients from U.S. universities. NSF 17-306. National Center for Science and Engineering Statistics. https://www.nsf.gov/statistics/2017/nsf17306/ static/report/nsf17306.pdf. Accessed 6 Dec 2021

7. Association of American Medical Colleges (2019) Diversity in medicine: facts and figures 2019. https://www.aamc.org/datareports/workforce/report/diversity-medicine-facts-and-figures2019. Accessed 6 Dec 2021

8. National Institutes of Health, National Cancer Center. CRCHD Diversity Training. https://www.cancer.gov/about-nci/organizati on/crchd/diversity-training. Accessed 6 Dec 2021

9. Northern Arizona University. Native American Cancer Prevention home page. https://in.nau.edu/nacp/. Accessed 6 Dec 2021

10. University of Arizona. Native American Cancer Prevention home page. https://cancercenter.arizona.edu/researchers/collaborativeresearch/nacp. Accessed 6 Dec 2021

Publisher's Note Springer Nature remains neutral with regard to jurisdictional claims in published maps and institutional affiliations. 